\title{
Platelet-rich plasma (PRP) a biogenic stimulator in treatment of primary atrophic rhinitis
}

\author{
Hany Samir Mostafa ${ }^{1 *}$ (D) and Essam Ezzat Ayad²
}

\begin{abstract}
Background: Primary atrophic rhinitis (1ry AR) is a chronic nasal disease characterized by the loss of mucociliary clearance and presence of viscid secretions and dried crusts that causes a characteristic foul odor, usually bilateral. A large range of treatment modalities had been tried, yet there is still no agreement upon a curative treatment with long-lasting success. The purpose of the study was to assess the value of platelet-rich plasma as a biogenic stimulator for healing acceleration in primary atrophic rhinitis.

A total of 78 cases clinically diagnosed to have primary atrophic rhinitis were included. Nasal endoscopy, Sino-Nasal Outcome Test- 25 questionnaire, mucociliary clearance assessment by saccharine transit time test, and biopsy specimens were achieved before 1 month and 6 months after the application of platelet-rich plasma in group A (cases) and platelet-poor plasma in group B (controls).

Results: All patients in group A showed endoscopic improvement and reduction in the incidence of the most frequently encountered symptoms before platelet-rich plasma injection including nasal crusts, 36 (92.30\%); foetor, 31 (79.48\%); nasal obstruction, 30 (76.92\%); anosmia, 17 (43.58\%); and epistaxis, 7 (17.94\%) to nasal crusts, 9 (23.07\%); foetor, 13 (33.33\%); nasal obstruction, 14 (35.89\%); anosmia, 13 (33.33\%); and epistaxis, 3 (7.69\%), 6 months after, and this was reflected in the reduction of the Sino-Nasal Outcome Test- 25 scores which was averaged 40 before plateletrich plasma to 9, 6 months after. Similarly, the mucociliary clearance time was significantly reduced after platelet-rich plasma injection; saccharine transit time test was initially averaged at $1980 \mathrm{~s}$ and got reduced to $920 \mathrm{~s}, 6$ months after platelet-rich plasma injection.
\end{abstract}

Conclusion: The use of platelet-rich plasma as a biogenic stimulator is a possible innovative less invasive approach that can be effective in repairing tissue dystrophy through further future studies.

Keywords: Primary atrophic rhinitis, Platelet-rich plasma, Mucociliary clearance, Saccharine transit time test

\section{Background}

Primary atrophic rhinitis (1ry AR) is a chronic nasal mucosal disease, characterized by extensive fibrosis leading to atrophic changes of the nasal mucosa and the underlying bone of the nasal turbinates resulting in the presence of viscid secretions and dried crusts that causes a characteristic foul odor, usually bilateral [1]. It is mainly seen in Africa, Asia, Eastern Europe especially Egypt,

\footnotetext{
* Correspondence: hanysam2002@yahoo.com

'Otorhinolaryngology Department, Fayoum University, Fayoum, Egypt

Full list of author information is available at the end of the article
}

India, Saudi Arabia, Philippines, and Poland [2, 3]. Where it can affect $0.3-1.0 \%$ of the population with special predominance in teens, and young adults show higher prevalence among females ( $\mathrm{F}: \mathrm{M}=5.6: 1)[4]$ and highly attributed to poverty and poor hygienic practices [5]. The exact etiology of primary atrophic rhinitis is still a matter of dispute; out of the various proposed etiologies, the theories of chronic bacterial rhinosinusitis most commonly caused by Klebsiella ozaenae [6], and autoimmunity is the most accepted [3, 7]. A diagnosis of primary atrophic rhinitis is essentially clinical; early stage of

\section{Springer Open}

(๑) The Author(s). 2020 Open Access This article is licensed under a Creative Commons Attribution 4.0 International License, which permits use, sharing, adaptation, distribution and reproduction in any medium or format, as long as you give appropriate credit to the original author(s) and the source, provide a link to the Creative Commons licence, and indicate if changes were made. The images or other third party material in this article are included in the article's Creative Commons licence, unless indicated otherwise in a credit line to the material. If material is not included in the article's Creative Commons licence and your intended use is not permitted by statutory regulation or exceeds the permitted use, you will need to obtain permission directly from the copyright holder. To view a copy of this licence, visit http://creativecommons.org/licenses/by/4.0/. 
disease may consist of foetor only, with nasal crustations. During late stages, full picture is usually seen and consists of a clinical trio of foetor, thick greenish crustations, and widened nasal cavities. Other symptoms include anosmia, headache, and epistaxis [1]. The histopathological picture consists of patches of squamotransformation of the normal respiratory epithelium which is pathognomonic for atrophic rhinitis seen in more than $80 \%$ of cases [8]. Metaplastic changes ranging from stratified squamous epithelium partial to severe in degree with or without keratinization [9]. Lamina propria and submucosa show chronic cellular infiltration, granulation, fibrosis, and glandular atrophy [10]. Two definite types of vascular changes are characteristic in AR: type I is more common (50-80\%), where endarteritis obliterans, periarteritis, and periarterial fibrosis of the terminal arterioles are seen. Type II is less common (20-50\%) and is associated with vasodilatation of the capillaries [11]. At the electron microscopic level, the cilia are either atrophied or completely lost affecting the mucociliary clearance property of the respiratory epithelium [12]. A large range of treatment modalities had been tried, e.g., local, systemic (medical), or surgical; however, the most adopted treatment is conservative (e.g., nasal irrigation, washes, drops, e.g., glucose-glycerin, mentholparaffin, antibiotics, and vasodilators) [13]. Many surgical modalities with aims like closure of the nasal cavities, e.g., the Young's operation and its modifications, or reducing the size of the nasal cavities, e.g., implants that may be autologous bone (cortical or cancellous chips), cartilage, muscle, fat; homologous lyophilized bone, fat, human placenta extract; or may be synthetics such as teflon, acrylics, silicone or silastic grafts, and many others, have been tried [14-16].

Platelet-rich plasma (PRP) is a platelet-rich concentrate of plasma proteins developed by dual-speed centrifugation of the whole blood. It has a higher concentration of growth factors and other cytokines [17]. Its numerous advantages include safety being autologous, do not need lengthened or complicated preparation, and the increased delivery of platelets and growth factors in treated areas; it can provide otorhinolaryngologists with a healing promoting packing material of the nose and ear or as a biogenic stimulator with autologous grafting materials. However, there are few published data on the application of plateletrich plasma: only 11 studies on various subspecialties (otology, rhinology, and laryngology) were revealed in the literature [18].

Since no treatment modality whether alone or combined provided long-lasting cure of 1ry AR as no one addressed the reversal of basic pathologic alteration in the microanatomy [19], we were derived to challenge the value of platelet-rich plasma as a biogenic stimulator for healing acceleration aiming to suggest a new treatment modality that might reverse the atrophic changes of nasal mucosa in primary atrophic rhinitis.

\section{Methods}

This study was carried out over the previous 3 years to assess the efficacy of autologous PRP on tissue regeneration in patients with primary atrophic rhinitis. A total of 78 cases clinically diagnosed to have primary atrophic rhinitis were randomly selected into two equal groups (39 patients) each: group A and group B. Patients with history of previous nasal trauma, nasal surgeries, systemic diseases known to cause secondary atrophic rhinitis, platelet-related hematologic disorders, or younger than 16 years old were excluded from the study. The aim of the procedure was clearly explained, and all patients gave their informed written consents.

Nasal endoscopy was done to confirm diagnosis, and clinical signs were recorded in all the cases; subjective scoring using the Sino-Nasal Outcome Test (SNOT-25) questionnaire [20] and mucociliary clearance assessment by saccharine transit time test (STT) according to Rodrigues et al. [21] (Fig. 1) were done before, 1 month and 6 months after the application of treatment.

Platelet-rich plasma (PRP) was prepared by drawing $10 \mathrm{ml}$ of blood sample from the patient. The blood was centrifuged at $3000 \mathrm{rpm}$ for $10 \mathrm{~min}$ "soft spin" to separate the blood into red blood cells, platelet-poor plasma (PPP), and a buffy coat. This was again centrifuged at $4000 \mathrm{rpm}$ for $10 \mathrm{~min}$ "hard spin" to separate platelet-rich plasma from platelet-poor plasma (Fig. 2). Approximately $1 \mathrm{ml}$ of platelet-rich plasma was obtained from $10 \mathrm{ml}$ blood after degranulating the platelet by adding $0.5 \mathrm{ml}$ of calcium chloride injected using $1 \mathrm{ml}$ insulin syringes into inferior turbinate, middle turbinate, floor, and septal area of both nostrils in group A, and $1 \mathrm{ml}$ of platelet-poor plasma (placebo treatment) was injected in the same manner in group B, and the patients were discharged from the hospital in the same day with oral antibiotics and anti-inflammatory agents for 1 week.

Biopsy specimens were obtained from the undersurface of middle third of inferior turbinate with the help of $0^{\circ}$ rigid nasal endoscope under local anesthesia before, 1 month and 6 months after the application of the treatments in both groups. Sections were prepared by routine paraffin processing, and hematoxylin-eosin staining was done, and the preparations were evaluated after being coded using light microscopy (Olympus BX51) by the same pathologist for detection of histopathological changes in the epithelium and submucosa, including epithelial metaplasia, goblet cell loss, cilia loss, inflammatory infiltration, and vascular changes; histopathological analysis was done using previous studies as reference for scoring over 3: 1 = minimal, $2=$ moderate, and $3=$ severe [22]. Mean, standard deviation, median, and lowest 


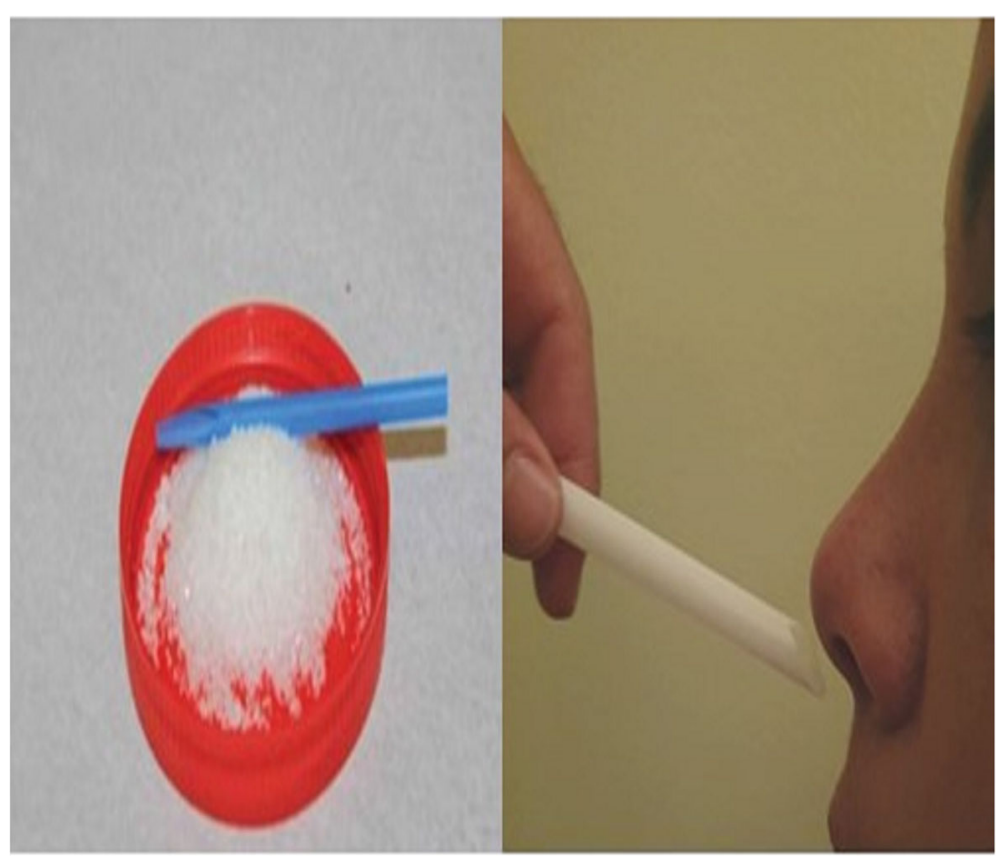

Fig. 1 Saccharine transit time test (STT)

and highest values were used in the descriptive statistics of the data. The distribution of the variables was controlled with Kolmogorov Smirnov test. The MannWhitney $U$ test was used for quantitative analysis. The $p$ value $\leq 0.05$ was considered the cut-off value for significance. The SPSS 22.0 program was used in analysis.

\section{Results}

Through the 78 subjects encountered and completed this study, the maximum incidence was in the third and fourth decades; the mean age was $28 \pm 0.45$ years (range 17-70 years); 29 cases were males, and 49 were females (M:F ratio was 1:1.68) (Table 1).

The mean duration of symptoms was $6 \pm 0.52$ years (range 2-54 years). The most common symptoms were nasal crusts, 74 (94.87\%); foetor, 71 (91.02\%); nasal obstruction, 59 (75.64\%); anosmia, 30 (38.46\%); and epistaxis, 11 (14.10\%). In Group A, the incidence was nasal crusts, 36 (92.30\%); foetor, 31 (79.48\%); nasal obstruction, 30 (76.92\%); anosmia, 17 (43.58\%); and epistaxis, 7 (17.94\%); all patients felt improvement in symptoms within 1 month of PRP, with nasal crusts, 21 (53.84\%); foetor, 25 (64.10\%); nasal obstruction, 21 (53.84\%); anosmia, 15 (38.46\%); and epistaxis, 7 (17.94\%). Six months after PRP, there was further improvement in symptoms with nasal crusts, 9 (23.07\%); foetor, 13 (33.33\%); nasal obstruction, 14 (35.89\%); anosmia, 13 (33.33\%); and epistaxis, $3(7.69 \%)$, and it was worth noting that those who did not respond well to the PRP treatment were having durations of symptoms longer than 4 years. As regrade group $\mathrm{B}$, there were minimal changes in the results obtained at the start of the study and 6 months after PPP injection where the incidence of the most common symptoms was nasal crusts, 37 (94.87), foetor, 35 (91.02\%); nasal obstruction, 29 (75.64\%); anosmia, 16 (41.02\%); and epistaxis, 5 (14.10\%).

None of the patients showed any local or systemic complication in response to the proposed treatment for each group.

\section{Histopathology}

Squamous metaplasia was seen in $80.4 \%$ of cases. Partial squamous metaplasia, total squamous metaplasia with marked absence of goblet cells, and total squamous metaplasia with keratinization were seen in $42.33 \%$, $33.88 \%$, and $12.66 \%$ of cases, respectively, and denuded epithelium in $3.44 \%$. In tunica propria, granulation tissue was noted in $39.22 \%$ of cases, chronic inflammatory cell infiltrates mainly lymphocytes in $38.44 \%$ of cases and fibrosis in $24.53 \%$ of cases. Basement membrane was thickened in $58.30 \%$ cases, ill-defined in $32.10 \%$, and normal in $8.10 \%$ cases. The changes in the blood vessels were observed as reduced vascularity $(56.66 \%)$, dilated blood vessels (22.33\%), endarteritis (14.33\%), and periarteritis (5.44\%). Mucosal glands were reduced both in number and size in $(58.66 \%)$ of cases and were absent in $34.14 \%$ of cases (Table 2).

The mean percent of change in epithelial metaplasia in group A was $1.83 \pm 0.75$ in the initial biopsy (before PRP), $1.63 \pm 0.45$ (1 month after PRP), and $1.38 \pm 0.32$ 


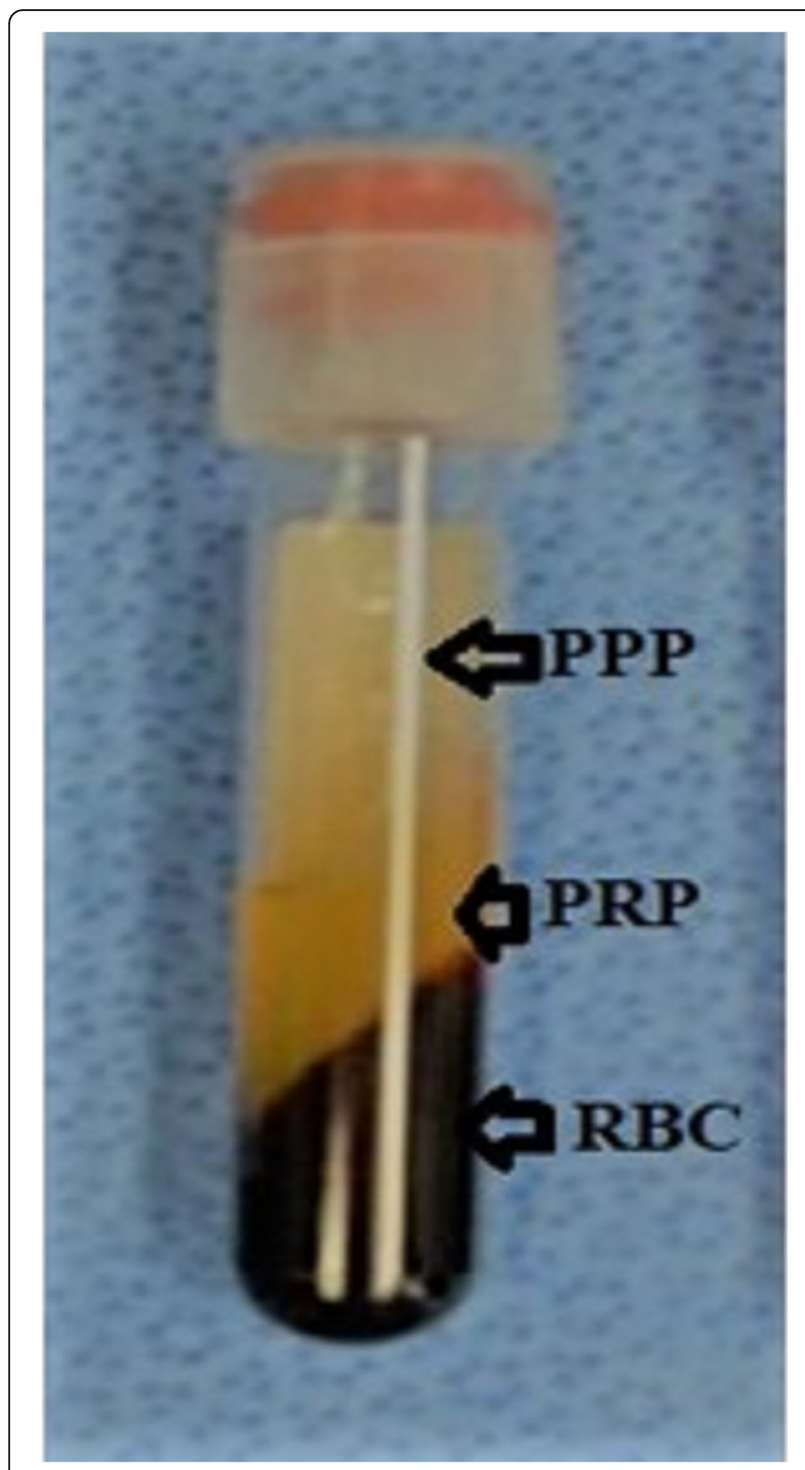

Fig. 2 Centrifuged blood into red blood cells (RBCs), platelet-rich plasma (PRP), and platelet-poor plasma (PPP)

(6 months after PRP). The mean percent of change in epithelial metaplasia in group B was $1.93 \pm 0.52$ in the initial biopsy (before PPP), $1.91 \pm 0.45$ ( 1 month after PPP), and $1.92 \pm 0.32$ (6 months after PPP) (Fig. 3a).

The mean percent of change in goblet cell loss in group A was $2.19 \pm 0.52$ in the initial biopsy (before

Table 1 The demographic data for both groups

\begin{tabular}{lll}
\hline & Group A & Group B \\
\hline Mean age \pm SD & $28.2 \pm 4.6$ & $28.4 \pm 4.9$ \\
M & 16 & 13 \\
F & 23 & 26 \\
Total & 39 & 39 \\
\hline
\end{tabular}

PRP), $1.93 \pm 0.45$ (1 month after PRP), and $1.83 \pm 0.32$ (6 months after PRP). The mean percent of change in goblet cell loss in group B was $2.21 \pm 0.75$ in the initial biopsy (before PPP), $2.25 \pm 0.45$ (1 month after PPP), and $2.22 \pm 0.32$ (6 months after PPP) (Fig. 3b).

The mean percent of change in inflammatory infiltration in group A was $2.17 \pm 0.75$ in the initial biopsy (before PRP), $1.63 \pm 0.52$ ( 1 month after PRP), and $1.30 \pm 0.55$ (6 months after PRP). The mean percent of change in inflammatory infiltration in group B was $2.17 \pm 0.45$ in the initial biopsy (before PPP), $2.04 \pm 0.52$ (1 month after PPP), and $2.11 \pm 0.32$ (6 months after PPP) (Fig. 3c).

The mean percent of change in vascular ectasia in group A was $2.17 \pm 0.75$ in the initial biopsy (before PRP), $2.11 \pm 0.45$ ( 1 month after PRP), and $1.93 \pm 0.45$ (6 months after PRP). The mean percent of change in vascular ectasia in group B was $1.83 \pm 0.75$ in the initial biopsy (before PPP), $1.93 \pm 0.45$ ( 1 month after PPP), and $2.17 \pm 0.32$ (6 months after PPP) (Fig. 3d).

No statistically significant difference was found when the incidence in the three biopsies was compared to each other in the same group or when compared to the results obtained in group B $(p>0.05)$.

\section{Sino-nasal outcome test (SNOT-25)}

In group A, SNOT-25 scores were averaged 40 initially (before PRP), with improvement to 11 (1 month after PRP) and to 9 (6 months after PRP). Where in group B, SNOT-25 scores were averaged 38 initially (before PPP), 37 (1 month after PPP), and 39 (6 months after PPP). A statistically significant difference was found when the SNOT-25 scores of the same case were compared to each or when compared to the results obtained in group $\mathrm{B}(p<0.05)$.

\section{Saccharine transit time test (STT)}

In group A, mucociliary clearance time was significantly reduced after PRP injection. STT was initially averaged at $1980 \mathrm{~s}$ with improvement to $1060 \mathrm{~s}$ after 1 month and $920 \mathrm{~s}$ after 6 months of PRP injection. Where in group B, there was no change in the initial average STT (1970 s) after 1 and 6 months of PPP injection. A statistically significant difference was found when the STT of the same case was compared to each or when compared to the results obtained in group B $(p<0.05)$.

\section{Discussion}

Atrophic rhinitis was described initially as early as 1876 by Fraenkel [23], although various medical and surgical treatments have been tried yet there is still no agreement upon a curative treatment. Since the clinical picture can be explained by the metaplasia of the normal ciliated columnar epithelium to nonciliated squamous epithelium and loss of mucociliary clearance, then the aim of 
Table 2 Histopathological features in group A, before, 1 month and 6 months after PRP treatment

\begin{tabular}{|c|c|c|c|c|}
\hline & Histopathological features & (\%) before PRP & (\%) 1 month after PRP & (\%) 6 months after PRP \\
\hline \multirow[t]{4}{*}{ A. Status of the epithelium } & 1. Partial squamous metaplasia & 42.33 & 41.33 & 39.33 \\
\hline & 2. Total squamous metaplasia & 33.88 & 32.66 & 32.66 \\
\hline & 3. Denuded epithelium & 3.44 & 1.88 & 0.64 \\
\hline & 4. Total squamous metaplasia with keratinization & 12.66 & 10.66 & 10.66 \\
\hline \multirow[t]{10}{*}{ B. Tunica propria } & 1. Granulation tissue & 39.22 & 38.66 & 34.66 \\
\hline & 2. Chronic inflammatory cellular infiltrate & 38.44 & 34.22 & 34.88 \\
\hline & 3. Fibrosis & 24.53 & 21.22 & 21.22 \\
\hline & 4. Granulation tissue with fibrosis & 24.53 & 23.22 & 23.22 \\
\hline & 5. Chronic inflammatory cellular infiltrate with fibrosis & 38.44 & 35.22 & 31.88 \\
\hline & 6. Basement membrane & & & \\
\hline & Thickened & 58.30 & 56.22 & 56.22 \\
\hline & III-defined & 32.10 & 29.88 & 29.88 \\
\hline & Normal & 8.10 & 15.88 & 17.22 \\
\hline & 1. Absence of glands & 23.14 & 19.27 & 17.88 \\
\hline \multirow[t]{2}{*}{ C. Mucous glands } & 2. Reduction in number and size of glands & 58.66 & 49.22 & 48.62 \\
\hline & 3. Normal glands & 11.66 & 16.22 & 16.22 \\
\hline \multirow[t]{4}{*}{ D. Blood vessels } & 1. Reduced vascularity & 56.66 & 49.22 & 40.88 \\
\hline & 2. Endarteritis & 14.33 & 13.22 & 12.28 \\
\hline & 3. Periarteritis & 5.44 & 4.66 & 4.66 \\
\hline & 4. Dilated blood vessels & 22.33 & 20.22 & 18.88 \\
\hline
\end{tabular}
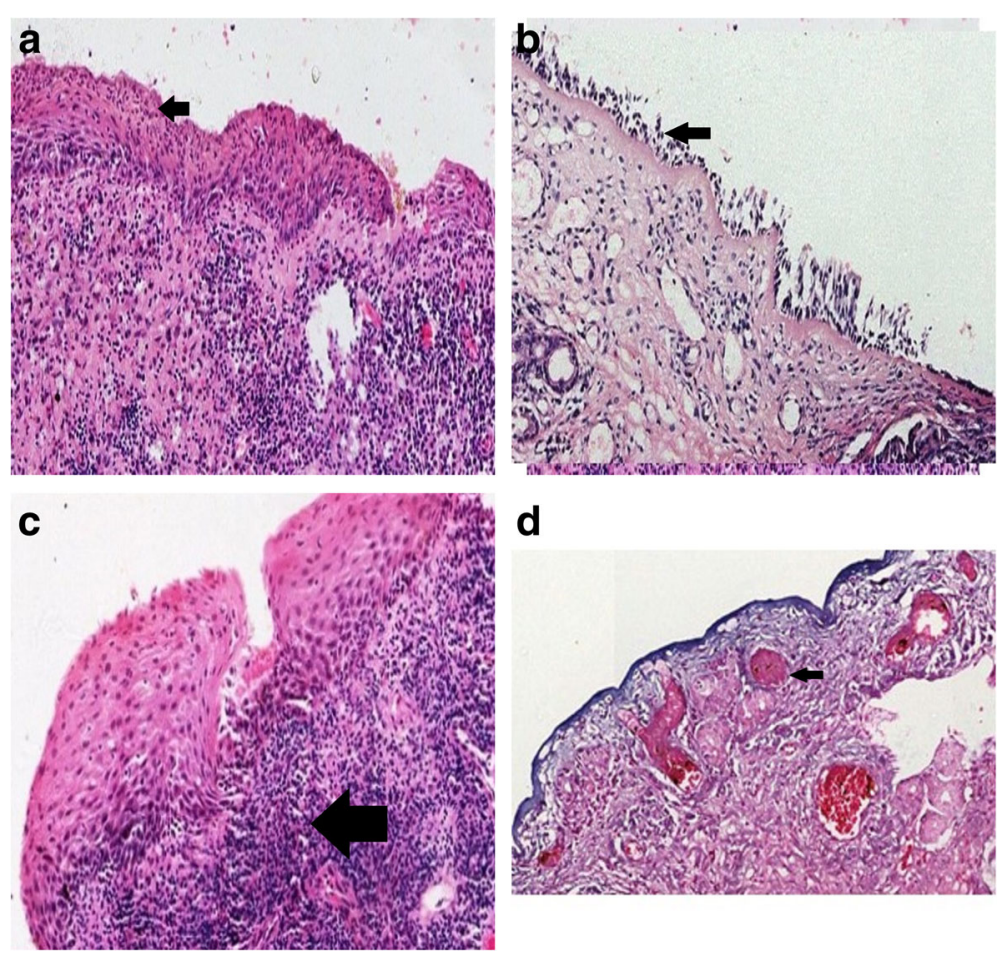

\section{d}

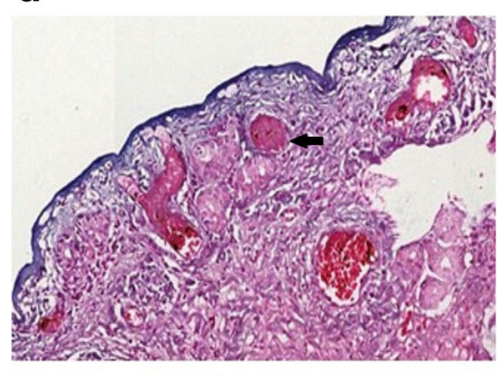

Fig. 3 a Squamous cell metaplasia (arrow); H\&E, original, magnification $\times 200$. b Erosion of the respiratory epithelium with cilia and goblet cell loss (arrow); H\&E, original, magnification $\times 200$. c Granulation tissue with abundant inflammatory cells (arrow); H\&E, original, magnification $\times 200$. d Stromal fibrosis, thick-walled vascular structures with abundant hemorrhage, and end arteritis obliterans (arrow); H\&E, original, magnification $\times 200$ 
the curative treatment with long-lasting success should be the reversal of this basic histopathologic change.

Only one report describing the use of platelet-rich plasma in treatment of atrophic rhinitis was identified. Friji et al. reported 5 patients had an autologous lipoaspirate applied to the inferior, middle turbinate, floor, and septum bilaterally with concomitant injection of platelet-rich plasma into the same areas as a biogenic stimulator to promote adipocytes survival and graft absorption reduction. Six months after the intervention, all 5 patients showed disappearance of nasal crustations and improvement of other symptom; endoscopic examination showed no signs of atrophy with the reappearance of glistening nasal mucosa. Sino-Nasal Outcome Test-20 scores had improved from an average of 36 to an average of 8 . In addition, the nasal mucociliary clearance time was significantly shorter after $960 \mathrm{~s}$ than before $1995 \mathrm{~s}$ intervention [19]. They attributed this to the stimulatory effect of mesenchymal stem cells within the fat graft, yet they could not proof or deny other nonmesenchymal mechanism for their results. The main drawbacks of Friji et al. study are the small number of cases and that the results are not substantiated by histopathological examination [19].

This article aimed at studding the benefit of the platelet-rich plasma as a biogenic stimulator that promotes regeneration to reverse the mucosal dystrophy which is pathognomonic for primary atrophic rhinitis. Although there were few commonalities in the techniques and evaluation methods adopted by Friji et al. study and this study, yet no fat graft was used (to exclude mesenchymal stem cell role), and nasal biopsy histopathologic examination was achieved [19].

All patients showed improvement in the endoscopic picture and felt reduction in the incidence of the most frequently encountered symptoms before PRP, and this was reflected in the SNOT-25 scores which was averaged 40 initially (before PRP) to 9 (6 months after PRP). Similarly, the mucociliary clearance time (evidence of ciliary regeneration) was significantly reduced after PRP injection. STT was initially averaged at $1980 \mathrm{~s}$ with improvement to $920 \mathrm{~s}$ after 6 months of PRP injection demonstrating mucosal regeneration, coinciding with Friji et al.'s report [19].

The incidence of the histopathological changes in the epithelium and submucosa, including epithelial metaplasia, absence of goblet cell, absence of cilia, inflammatory infiltration, and vascular changes, showed improvement as regards the 1 month and 6 months after PRP biopsies compared to the initial biopsies.

These initial results could not prove the histopathologic alternation towards the mucosal regeneration after the PRP treatment as no statistically significant difference was found when the three biopsies in group A were compared to each other or when compared to the results obtained in group B. Yet the improvement in patient clinical picture by nasal endoscopy, symptoms by SNOT score, and mucociliary clearance by STT can demonstrate it with great similarity to the results obtained through more invasive approaches as the adipocyte-derived stem cells dermofat grafts.

\section{Conclusion}

Current managements of atrophic rhinitis are ineffective for long-term cure; in light of this study, the use of PRP as a biogenic stimulator is a possible innovative less invasive approach that can be effective in repairing tissue dystrophy through further future studies.

\section{Abbreviations \\ 1ry AR: Primary atrophic rhinitis; PRP: Platelet-rich plasma; PPP: Platelet-poor plasma; SNOT-25: Sino-Nasal Outcome Test questionnaire; STT: Saccharine transit time test}

\section{Acknowledgements}

Not applicable

\section{Authors' contributions}

HS designed and executed the clinical part of this study, shared in the analysis and interpretation of the patient's data, and in writing the manuscript of the study. EA performed the histopathological examination of the nasal biopsies and was a major contributor in writing the manuscript. Both authors read and approved the final manuscript.

\section{Funding}

The authors declare that they did not receive funding for this research.

\section{Availability of data and materials}

The data sets during and/or analyzed during the current study available from the corresponding author on reasonable request.

\section{Ethics approval and consent to participate}

This study was approved by the institute ethics and research committee in the Department of Otorhinolaryngology-Fayoum University Hospital. The aim of the procedure was clearly explained, and all patients gave their informed written consents.

Consent for publication

Not applicable.

\section{Competing interests}

The authors declare that they have no competing interests.

\section{Author details}

${ }^{1}$ Otorhinolaryngology Department, Fayoum University, Fayoum, Egypt.

${ }^{2}$ Pathology Department, Cairo University, Cairo, Egypt.

Received: 8 June 2020 Accepted: 22 July 2020

Published online: 26 October 2020

\section{References}

1. Sampan S. Bist, Manisha Bisht and Jagdish P. Purohit: [Primary atrophic rhinitis: a clinical profile, microbiological and radiological study] ISRN Otolaryngology Volume 2012, Article ID 404075, 6 pages.

2. Lobo CJ, Hartley C, Farrington WT (1998) Closure of the nasal vestibule in atrophic rhinitis - a new non-surgical technique. J Laryngol Otol 112:543-546

3. Zohar Y, Talmi YP, Strauss M, Finkelstein Y, Shvilli Y (1990) Ozena revisited. J Otolaryngol 19:345-349

4. Dutt SN, Kameswaran M (2005) The aetiology and management of atrophic rhinitis. J Laryngol Otol 119(11):843-852 
5. V. N. Chaturvedi, S. Kameswaran and M.Kameswaran: [Atrophic rhinitis and nasal miasis, in ENT disorders in a tropical environment ] MERF Publications, 1999 2nd edition: 119-128.

6. Bunnag C, Jareoncharsii P, Tansuriyawong P, Bhoth-isuwan W, Chantarakul N (1999) Characteristics of atrophic rhinitis in Thai patients at the Siriraj Hospital. Rhinology 37(3):125-130

7. Artiles F, Bordes A, Conde A, Dominguez S, Ramos JL, Suarez S (2000) Chronic atrophic rhinitis and Klebsiella ozaenae infection. Enfermedades Infecciosas y Microbiologia Clinica 18(6):299-300

8. Chen HS (1984) Desquamation and squamotransformation of rhinomucosa as a prodromal sign of atrophic rhinitis. J Otorhinolaryngol Its Related Specialties 46(6):327-328

9. Udrescu S, Firică D (1971) Proposed modification of the Lautenschläger method for re-calibration of the nasal fossae in ozena. Otorinolaringologie. $16: 275-278$

10. Sajjad A (2011) A new technique for nasal stent fabrication for atrophic rhinitis: a clinical report. J. Prosthodont 20:326-328

11. Taylor M, Young A (1961) Histopathological and histochemical studies on atrophic rhinitis. J Laryngol Otol 75:574-590

12. Goldenberg D, Danino J, Netzer A, Joachims HZ (2000) Plastipore implants in the surgical treatment of atrophic rhinitis: technique and results. Otolaryngol Head Neck Surg 122:794-797

13. SN Dutt, M Kameswaran: [ The aetiology and management of atrophic rhinitis]. J Laryngol Otol. 2005; 119: 843-852

14. El Kholy A, Habib O, Abdel-Monem MH, Abu SS (1998) Septal mucoperichondrial flap for closure of nostril in atrophic rhinitis. Rhinology 36:202-203

15. Gadre KC (1973) Modification in the technique of closure of the nostril. J Laryngol Otol 87:903-904

16. Sinha SM, Sardana DS, Rjvanshi VS (1977) A nine-year review of 273 cases of atrophic rhinitis and its management. J Laryngol Otol 91:591-600

17. Sclafani AP, Azzi I (2015) Platelet preparations for use in facial reju-venation and wound healing: a critical review of current literature. Aesthet Plast Surg 39:495-505

18. Stavrakas M, Karkos PD, Markou K, Grigoriadis N et al (2016) J Laryngol Otol 130:1098-1102

19. Friji MT, Gopalakrishnan S, Verma SK, Parida PK, Mohapatra DP (2014) New regenerative approach to atrophic rhinitis using autologous lipoaspirate transfer and platelet rich plasma in five patients. Clin Otolaryngol Oct 39(5): 289-292. https://doi.org/10.1111/coa.12269

20. Payne SC.: [Empty nose syndrome: what are we really talking about?]. Otolaryngol Clin North Am 2009; 42:331 -7 [ix-x].

21. Rodrigues F, Freire AP, Uzeloto J, Xavier R, Ito J, Rocha M, Calciolari R, Ramos D, Ramos E (2019) Particularities and Clinical Applicability of Saccharin Transit Time Test. Int Arch Otorhinolaryngol 23:229-240

22. Parkins CS, Fowler JF, Yu S (1983) [Murine model of lip epidermal/mucosal reactions to X-irradiation]. Radiother. Oncol. 1:159-165

23. Shehata MA (1996) Atrophic rhinitis. Am J Otolaryngol 17(2):81-86

\section{Publisher's Note}

Springer Nature remains neutral with regard to jurisdictional claims in published maps and institutional affiliations.

\section{Submit your manuscript to a SpringerOpen ${ }^{\circ}$ journal and benefit from:}

- Convenient online submission

- Rigorous peer review

- Open access: articles freely available online

- High visibility within the field

- Retaining the copyright to your article

Submit your next manuscript at $\boldsymbol{\nabla}$ springeropen.com 